\title{
Scoring system to predict nodal metastases in patients with early-stage esophageal cancer: An outstanding tool to complement multidisciplinary, team-based care
}

\author{
Mara B. Antonoff, MD \\ From the Department of Thoracic and Cardiovascular Surgery, University of Texas MD Anderson Cancer Center, \\ Houston, Tex. \\ Disclosures: Author has nothing to disclose with regard to commercial support. \\ Received for publication Aug 6, 2017; accepted for publication Aug 8, 2017. \\ Address for reprints: Mara B. Antonoff, MD, Department of Thoracic and Cardiovascular Surgery, University of \\ Texas MD Anderson Cancer Center, 1400 Pressler St, Unit 1489, Houston, TX 77030 (E-mail: mbantonoff@ \\ mdanderson.org). \\ J Thorac Cardiovasc Surg 2017;154:1794-5 \\ $0022-5223 / \$ 36.00$ \\ Copyright (C) 2017 by The American Association for Thoracic Surgery \\ http://dx.doi.org/10.1016/j.jtcvs.2017.08.007
}

Endoscopic mucosal resection (EMR) has been increasingly used in recent years for T1 adenocarcinoma of the esophagus, often as definitive local therapy for T1a tumors, with some clinicians further advocating for application to T1b tumors, with diagnostic as well as potential therapeutic benefit in select cases. ${ }^{1,2}$ For patients with such early-stage tumors, the presence of nodal metastases are incredibly relevant, as they are the most reliable determinant of long-term survival in patients with superficially invasive disease. ${ }^{3}$ Recognizing that approximately $10 \%$ to $15 \%$ of patients with $\mathrm{T} 1$ disease have nodal metastases, it is critically important for us to be able to identify a cohort at greatest risk for nodal involvement because they are dramatically less likely to do well following esophageal preservation. ${ }^{4}$

Weksler and colleagues ${ }^{5}$ describe their use of the National Cancer Database (NCDB) to elucidate key variables that influence likelihood of nodal metastases among patients with $\mathrm{T} 1$ esophageal adenocarcinoma and subsequently use these data to create a scoring system to predict risk of nodal disease. ${ }^{5}$ Through this sophisticated and well-written contribution, the investigators provide us with a tool to counsel patients and discuss their cases, aiming to clarify which patients would most safely be observed following EMR as well as those who merit more aggressive resection in the form of esophagectomy. Certainly, this is not the first attempt to define risk of nodal metastases for $\mathrm{T} 1$ esophageal cancer patients, with previous authors $^{6-8}$ developing risk-stratified groups as well as scoring systems similar to that described by Weksler and colleagues. ${ }^{5}$ However, this article boasts several advantages over prior publications in its excellent attempt to close the existing knowledge gap. Querying a national database such as the NCDB, Weksler and colleagues ${ }^{5}$ conducted their analyses with a cohort 5 times greater than the largest previous similar study, with nearly 1300 patients in this report. Although overall results were analogous among

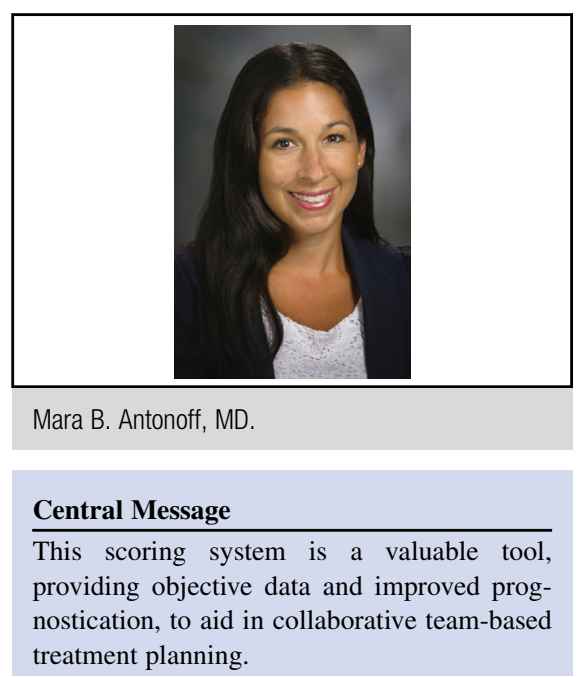

See Article page 1787

these reports, this publication has the advantage of being a quantitative scoring system rather than a means of grouping into low and high risk. Further, compared with the one previous scoring system, the model developed by Weksler and colleagues ${ }^{5}$ demonstrated greater discrimination among patients with lower risk of nodal metastases.?

Overall, this is an outstanding contribution that will become a seminal piece of literature and benefits our specialty substantially. Of course, as with any research article, there are inherent limitations, and the authors do an excellent job of acknowledging those that are specifically related to the NCDB (retrospective study, inability to verify individual data points, evidence of inadequate lymph node harvests among cases in the $\mathrm{NCDB}$, and lack of lymphovascular invasion information in the NCDB for all but 4 years). Before applying this scoring system, we should also consider additional possible limitations beyond those inherent to the database. The authors appropriately acknowledge that EMR was already somewhat popular during the era of the study, and that the evaluation of patients who underwent esophagectomy may select an inherently higher risk group of individuals, with "worse disease" that was appreciated by their treating clinicians and led to the fact that they were not offered EMR. Another important consideration is the applicability of pathologic data from NCDB patients to 
other patients based on endoscopic findings. It is not clear that data obtained via endoscopic ultrasound and esophagogastroduodenoscopy are perfect representations of ultimate pathologic findings upon esophagectomy, as u-stage does not always match p-stage. Ultimately, the best way to overcome this obstacle would be to validate this scoring system that was developed with pT1a-b patients after esophagectomy by testing it in patients with cT1a-b and uT1a-b tumors, as those are the individuals in whom it will ultimately be applied in practice. Such an undertaking would be a much appreciated follow-up contribution to the literature. Nonetheless, despite its limitations, this article is strides ahead of any existing paper on the topic, and the authors have successfully achieved the objectives that they sought to answer.

In their conclusion, the authors suggest that surgeons, gastroenterologists, and multidisciplinary tumor boards might use this system to identify those patients who should be observed and those who should undergo esophagectomy following EMR. Further, they propose that induction therapy might be given to some patients with $\mathrm{T} 1 \mathrm{~b}$ tumors with very high risk of nodal metastasis based on the scoring system. Certainly, this is an excellent scoring system, and it provides objective data for multidisciplinary discussions. However, emphasis ought to be placed on the imperative role of interdisciplinary collaboration and tumor board consensus for such decisions. After all, even with enhanced prediction of potential outcomes and improved prognostication with this scoring system, it is only through collaborative expertise and team-based treatment planning that we can truly achieve optimal results for our patients.

\section{References}

1. Manner H, Pech O, Heldmann Y, May A, Phol J, Behrens A, et al. Efficacy, safety, and long-term results of endoscopic treatment for early stage adenocarcinoma of the esophagus with low-risk sm1 invasion. Clin Gastroenterol Hepatol. 2013;11: 630-5; quiz e645.

2. Pech O, Bollschweiler E, Manner H, Leers J, Ell C, Holscher AH Comparison between endoscopic and surgical resection of mucosal esophagea adenocarcinoma in Barrett's esophagus at two high-volume centers. Ann Surg. 2011;254:67-72.

3. Lorenz D, Origer J, Pauthner M, Graupe F, Fisseler-Eckhoff A, Stotle M, et al Prognostic risk factors of early esophageal adenocarcinomas. Ann Surg. 2014; 259:469-76.

4. Gaur P, Sepesi B, Hofstetter WL, Correa AM, Bhutani MS, Vaporciyan AA, et al A clinical nomogram predicting pathologic lymph node involvement in esophageal cancer patients. Ann Surg. 2010;252:611-7.

5. Weksler B, Kennedy KF, Sullivan JL. Using the National Cancer Database to create a scoring system that identifies patients with early-stage esophageal cancer at risk for nodal metastases. J Thorac Cardiovasc Surg. 2017:154:1787-93.

6. Davison JM, Landau MS, Luketich JD, McGrath KM, Foxwell TJ Landsittel DP, et al. A model based on pathologic features of superficial esophageal adenocarcinoma complements clinical node staging in determining risk of metastasis to lymph nodes. Clin Gastroenterol Hepatol. 2016;14: 369-77.e3.

7. Lee L, Ronellenfitsch U, Hofstetter WL, Darling G, Gaiser T, Lippert C, et al. Predicting lymph node metastases in early esophageal adenocarcinoma using a simple scoring system. J Am Coll Surg. 2013;217:191-9.

8. Barbour AP, Jones M, Brown I, Gotley DC, Martin I, Thomas J, et al. Risk stratification for early esophageal adenocarcinoma: analysis of lymphatic spread and prognostic factors. Ann Surg Oncol. 2010;17:2494-502. 